\title{
Ceremonial y protocolo: el tránsito al posmodernismo
}

\author{
Dr. Serafín Piñeiro Rodríguez | serafinpr@gmail.com \\ Instituto Mediterráneo Estudios de Protocolo
}

\author{
Palabras clave \\ ceremonial; protocolo; modernismo líquido; \\ posmodernismo; simbología \\ Sumario \\ 1. Introducción. 1.1 Sociedades posmodernas \\ (líquidas). 1.2 Estructuras de poder y protocolo. 1.2.1 \\ Monarquía de Alfonso XIII. 1.2.2 II República. 1.2.3 \\ Dictadura franquista. 1.2.4 Monarquía Parlamentaria \\ de Juan Carlos I. 1.2.5. Reinado de Felipe VI: \\ posmodernismo. 2. Metodología. 3. Resultados. 3.1 \\ De Monarquía a II República. 3.2 De II República a \\ Dictadura. 3.3 De Dictadura a Monarquía. 3.4 Relación \\ de orden temporal. 3.5 Cambios de normativa \\ protocolaria. 4. Conclusiones. 5. Bibliografía. 6. Notas
}

\section{Resumen}

Este trabajo se pasea por los últimos cien años de la historia de España (1917-2017), tratando de resaltar el tránsito experimentado por el binomio ceremonial-protocolo en esa metamorfosis social que llevó a la nación del modernismo del primer cuarto del siglo XX, a este posmodernismo líquido en el que algunos sociólogos, como Zygmunt Bauman, nos sitúan. Así mismo, teniendo en cuenta las distintas estructuras de poder acaecidas y a través del análisis documental, trata de inferir cómo se llevó a cabo la gestión tanto de las representaciones

plásticas más evidentes de las estructuras de poder (simbología), como de la escenificación de los actos llevados a cabo (ceremonial) y; en su caso, de las normas promulgadas que los sustentaron (protocolo). Así mismo, trata de averiguar si existe una relación de orden temporal entre el proceso de asentamiento de una nueva estructura de poder y la transformación del trinomio simbología-ceremonial-protocolo. Por último se probará que, para que se produzca un cambio en las normas protocolarias de un país, o varía su situación política, social o económica, o existe un poder soberano político que decide dicho cambio.

\section{Cómo citar este texto:}

Serafín Piñeiro Rodríguez (2017): "Ceremonial y protocolo: el tránsito al posmodernismo", en Miguel Hernández Communication Journal, nº, pp. 319 a 345. Universidad Miguel Hernández, UMH (Elche-Alicante). Recuperado el de de 20__ de: @ink

del artículo en mhjournal.org] 


\title{
Ceremonial and protocol: The transition to postmodernism
}

\author{
Dr. Serafín Piñeiro Rodríguez | serafinpr@gmail.com \\ Instituto Mediterráneo Estudios de Protocolo
}

\section{Keywords}

ceremonial; protocol; liquid modernism; postmodernism; symbology.

\section{Summary}

1. Introduction. 1.1 The Postmodern societies

(liquid). 1.2 Power and protocol structures. 1.2.1

The Monarchy of Alfonso the XIII. 1.2.2 The II

Republic. 1.2.3 Franco dictatorship. 1.2.4 The

Parliamentary Monarchy of Juan Carlos the I.

1.2.5 The Reign of Philip VI: Postmodernism. 2.

Methodology. 3. Results. 3.1 From Monarchy to

the II Republic. 3.2 From the II Republic to

Dictatorship. 3.3 From Dictatorship to Monarchy.

3.4 Temporal order relationship. 3.5 Changes in protocol regulations. 4. Conclusions. 5.

Bibliography 6. Notes

\section{Abstract}

The main objective of this paper is to analyze cartel party tendencies toward professionalization of communicative institutional processes (Mair, 2015).

The main role of the media in a audience democracy is indisputable (Manin, 1998). So the media politics are one of the main features of public space.

In this way, Political parties have become platforms of placement of their leaders to occupy the largest number of institutional positions. Consequently, this phenomenon has spread as a common practice of our political system. The emergence of partisan elite, which has professionalized itself in high politicalinstitutional positions, has colonized the leadership of public institutions. It has given rise to relations of dependence between political elites and institutions. This situation explains the constant need for the search for legitimacy with strategies, one of the main being communicative.

\section{How to cite this text:}

Serafín Piñeiro Rodríguez (2017): "Cartelization process in institutionalized environments: legitimation and political communication”, en Miguel Hernández Communication Journal, nº, pp. 319 to 345. Universidad Miguel Hernández, UMH (Elche-Alicante). Accessed 20_ in: [paper link in mhjournal.org] 


\section{Introducción}

Abordar la gestión de la influencia y la reputación en las sociedades postmodernas líquidas desde el punto de vista del binomio ceremonialprotocolo, implica asociar el relevante papel que juega el protocolo, como generador de influencia en las estructuras de poder que rigen las sociedades; así como, lo determinante que resulta para aquellas el uso del ceremonial a la hora de alcanzar la pretendida reputación.

Dadas las vicisitudes de España hasta alcanzar el status de sociedad democrática avanzada, el trabajo trata de resaltar el complejo tránsito experimentado por el binomio ceremonial-protocolo, en esa metamorfosis social que ha llevado a España desde el modernismo de 1917, en pleno reinado de Alfonso XIII, hasta la Monarquía de Felipe VI encuadrada en este posmodernismo líquido actual, donde nos ubican algunos sociólogos y en el que el desafecto a los símbolos de la Nación es una realidad tangible. Para ello, nos permitimos agrupar el período de la II República y el de la Dictadura en una sola etapa que llamaremos de Tránsito.

Teniendo en cuenta las estructuras de poder tan dispares acaecidas en el período considerado, trataremos de ver cómo fue la gestión de las representaciones plásticas más evidentes de estas estructuras de poder (los símbolos), así como del ceremonial de los actos solemnes llevados a cabo y, en su caso, de las normas de protocolo que los ampararon. Respecto a estos tres elementos, se tratará de averiguar si los cambios efectuados al instaurarse la República, la Dictadura y la Monarquía, guardan alguna relación de orden temporal.

Por último, se constatará el argumento de Joaquín Martinez-Correcher (2002), al sostener que para que se produzca un cambio en las normas protocolarias de un país, o varía su situación política, social o económica; o existe un poder soberano político que decide cambiarlas.

\subsection{Sociedades posmodernas (líquidas)}

El Real Diccionario de la Lengua Española (DRAE) ${ }^{1}$ define la posmodernidad como "Movimiento artístico y cultural de fines del siglo XX, caracterizado por su oposición al racionalismo y por su culto predominante de las formas, el individualismo y la falta de compromiso social".

Fredric, J. (1991: 9), señala que "El fin de la ideología, del arte, de las clases sociales; la crisis del leninismo, la socialdemocracia o el estado del bienestar, etc.; tomados en su conjunto [...] pueden considerarse constitutivos de lo que cada vez con mayor frecuencia se llama posmodernismo". En cambio, 
Redondo Gálvez, G. (1993: 97), defiende que "a pesar del uso y abuso del concepto posmodernidad, no se ha llegado ni con mucho a tal estadio. En la Modernidad estábamos, y en la Modernidad seguimos estando".

Finalmente Zygmunt Bauman ${ }^{2}$ acuña el término "modernidad líquida" escapando del confuso concepto que representa el posmodernismo y, con su metáfora de lo líquido versus lo sólido, señala que el capitalismo industrial, la familia patriarcal, los Estados o los partidos políticos, entre otros (a los que engloba en una "modernidad sólida" y estable), han dado paso una modernidad líquida (posmodernidad) 3 , en la que las relaciones sociales son inestables, brotan las incertidumbres del individuo (sus miedos), la imposibilidad de planificar a largo plazo y el olvido del referente histórico y familiar.

"Son la inseguridad del presente y la incertidumbre sobre el futuro las que incuban y crían nuestros temores más imponentes e insoportables" (Bauman, Z. 2007: 42). Por tanto, este modernismo líquido capaz de ocupar cualquier volumen, y a cualquier hora, sintoniza bien con un mundo globalizado en el que cohabitan sumergidos vocablos como: Brexit, populismo, yihadismo, macronismo y personajes dispares cuya meta última bien pudiera ser alcanzar el poder político.

\subsection{Estructuras de poder y protocolo}

Las sociedades evolucionan, pero siempre serán los gobernantes quienes tratarán de diseñar una serie de normas para asentar su relación con los gobernados. A veces esas normas, catalizadoras del orden, son pactadas con la sociedad, y se habla de una estructura de poder democrática y legitimada; y otras, son impuestas por la fuerza humana (o la divina), y estaríamos frente a estructuras totalitarias.

Dentro de estas normas nos fijaremos en las que asientan la simbología, el ceremonial y el protocolo de esas estructuras de poder. Acudiendo al DRAE, vemos que define ceremonial como: "Serie o conjunto de formalidades para cualquier acto público o solemne"; y protocolo como: "Conjunto de reglas establecidas por norma o por costumbre para ceremonias y actos oficiales o solemnes". Puede convenirse pues, que el ceremonial es responsable de la "forma" o de la escenificación; mientras que el protocolo lo es de la "norma" o la ordenación.

Finalizando el siglo XX autores como Otero Alvarado (2000), entre otros, contribuyen a variar el enfoque palatino del término protocolo, vinculándolo con las teorías de la comunicación y reclamando su papel como vía de proyección de las representaciones plásticas de las estructuras de poder. Para 
esta corriente, el protocolo se convierte en excelente herramienta de comunicación (no verbal) entre las instituciones y sus públicos.

A continuación, de forma somera, se verán las tres trasformaciones experimentadas por la estructura de poder en España durante los últimos cien años (1917-2017), así como las nuevas simbologías que llevaron aparejadas dichos cambios políticos, la escenificación o ceremonial aplicado en los actos más o menos solemnes y las normas más importantes de protocolo que los sustentaron

\subsubsection{Monarquía de Alfonso XIII.}

La monarquía de Alfonso XIII (1917) se asienta en la Constitución de 1876, que concede al Rey la opción de otorgar la jefatura del Estado al partido conservador o al liberal. A pesar de la cruzada anticlerical de los liberales, la Iglesia Católica preserva gran influencia política en la estructura de poder y la Carta Magna reconoce el catolicismo como religión del Estado.

El golpe militar de Primo de Rivera es un punto de inflexión en esta etapa. Gómez Navarro (1991:116), apunta que "llegado 1923 Alfonso XIII se convence de que el sistema de partidos está colocando la política por encima de los intereses nacionales, y consiente el golpe de estado de Rivera que liquida la Constitución". Este consentimiento espoleó al republicanismo y terminó afectando al bipartidismo de forma que, tras la dimisión de Rivera (1930), la situación es crítica y los resultados de las elecciones de abril (1931), obligan al Monarca a abandonar España. Para más información consultar Carasa Soto (1991)

Para Giraud, E. (1938) "la monarquía limitada ha servido de enlace pacífico entre la monarquía absoluta y la democracia parlamentaria".

Alfonso XIII gustaba del ceremonial de la Cobertura de los Grandes de España, de la Toma de la Almohada, de imposición del Toisón, las Capillas Públicas, etc. González Cuevas, PC. (2003), respecto a la ceremonia de Cobertura de los Grandes, señala que "[...], como la mayor parte del ceremonial de entonces, tenía un acusado carácter borgoñón mezclado con las aportaciones de la dinastía borbón”. Durante su reinado se promulgaría:

Real Orden (R.O.) del Rey de 15 de enero 1908, que regula las recepciones en el Salón del Trono y dispone el orden para la entrada y desfile ante S.M, que establece un orden por jerarquías de las siete categorías que ocuparán las siete salas del Palacio Real. Salvo los miembros del Consejo de Estado, los grandes de España y primogénitos preceden al resto de autoridades de la Administración; les siguen las personas importantes (privadas), componentes de Casa Real, Capitán General y mandos militares y el Cuarto Militar. 
La crónica de la recepción del 24 de enero de 1931 (Abc pp. 22-24) ${ }^{5}$, señala que la Orden se aplicó con rigor y que el desfile ante el Rey se prolongó más de tres horas. Martínez-Correcher, J. (1997: 28), argumenta que "el detonante de esta publicación fue la mayoría de edad constitucional y posterior matrimonio real de Alfonso XIII".

Real Orden Circular (R.O.C.) de 19 enero 1926, sobre el Besamanos y recepciones para los Besamanos donde no residan Sus Majestades (SS.MM), bajo la dictadura de Rivera que apreció necesaria esta norma pionera que recogía la prelación de autoridades y corporaciones en los actos a celebrar en cualquier parte de España cuando no asistieran SS.MM.

Real Decreto (R.D.) de 31 diciembre 1921, que aprueba el Reglamento de honores a la voz y al cañón en los buques de la Armada. Su art. 93 reza: "El Día del Corpus se realizarán tres salvas de 15 cañonazos: al salir el Santísimo Sacramento de la iglesia, a mitad de la carrera y al entrar al templo [...]"6.

Al Monarca se le debe que por primera vez ondeara la bandera nacional en edificios públicos los días festivos y que comenzara a sonar la Marcha Granadera a modo de himno nacional, como se puede contrastar en la normativa de la tabla $n^{\circ} 1$. (Martínez-Correcher, J. 2014).

Al final del reinado, la etiqueta fue perdiendo esplendor y según Almagro de San Martín, M. (1946: 134), "con la democratización paulatina del mundo, que allana las cumbres, fue cayendo el auge fastuoso de las ceremonias regias, faltas de la savia que había de comunicarles una aristocracia cada vez más empobrecida".

Tabla $\mathrm{n}^{\circ}$ 1: Normativa relevante promulgada I. Fuente. Elaboración propia.

\begin{tabular}{|l|l|}
\hline \multicolumn{1}{|c|}{ NORMATIVA } & LEGISLA SOBRE \\
\hline $\begin{array}{l}\text { R.O. de } 15 \text { enero } \\
1908\end{array}$ & $\begin{array}{l}\text { Sobre recepciones en el salón del Trono y desfile } \\
\text { ante S.M. }\end{array}$ \\
\hline $\begin{array}{l}\text { Decreto de 25 } \\
\text { enero } 1908\end{array}$ & $\begin{array}{l}\text { La Bandera ondeará en edificios públicos los días de } \\
\text { Fiesta Nacional }\end{array}$ \\
\hline $\begin{array}{l}\text { R.O.C. de 27 agosto } \\
1908\end{array}$ & $\begin{array}{l}\text { Que las bandas militares ejecuten la Marcha Real } \\
\text { Española }\end{array}$ \\
\hline $\begin{array}{l}\text { ROC 20 octubre } \\
1908\end{array}$ & $\begin{array}{l}\text { Lugar a ocupar en actos oficiales Jefes del Fomento } \\
\text { y Delegados regios }\end{array}$ \\
\hline
\end{tabular}




\begin{tabular}{|c|c|}
\hline $\begin{array}{l}\text { R.O. } 15 \text { noviembre } \\
1916\end{array}$ & Reitera la R.O. de 15 de enero de 1908 \\
\hline $\begin{array}{lll}\text { R.D. } & \text { de } & 31 \\
\text { diciembre } & 1921\end{array}$ & $\begin{array}{l}\text { Reglamento de honores a la voz y al cañón en } \\
\text { buques (R.D. } 4 \text { enero 1922), Gaceta Madrid núm.17 } \\
\text { (17 enero 1922) }\end{array}$ \\
\hline $\begin{array}{l}\text { R.O, de } 31 \text { enero } \\
1923\end{array}$ & ss \\
\hline $\begin{array}{l}\text { R. O, de } 30 \\
\text { septiembre } \\
1924\end{array}$ & Sobre colocación Delegado Hacienda \\
\hline $\begin{array}{lcc}\text { R. O, } & 29 & \text { de } \\
\text { noviembre } & 1925\end{array}$ & $\begin{array}{l}\text { Sobre prelación de las Reales Academias en actos } \\
\text { oficiales }\end{array}$ \\
\hline $\begin{array}{l}\text { R.O.C. de } 19 \text { enero } \\
1926\end{array}$ & para Besamanos donde no acudan SS. \\
\hline $\begin{array}{l}\text { R.O.C. de } 20 \text { mayo } \\
1927\end{array}$ & $\begin{array}{l}\text { Presidencia actos oficiales si concurren Gobernador } \\
\text { civil y C. Gral. }\end{array}$ \\
\hline $\begin{array}{l}\text { R.O.C. de } 11 \text { junio } \\
1927\end{array}$ & $\begin{array}{l}\text { Normas en actos a que concurra el Cuerpo } \\
\text { Diplomático extranjero. }\end{array}$ \\
\hline $\begin{array}{l}\text { Orden de } 17 \text { dic. } \\
1928\end{array}$ & $\begin{array}{l}\text { Que el Gobernador Civil ha de conocer la llegada de } \\
\text { autoridades }\end{array}$ \\
\hline $\begin{array}{l}\text { Orden de } 27 \text { sept. } \\
1929\end{array}$ & $\begin{array}{l}\text { le } 20 \text { de mayo de } 1927 \text { en ausencia del } \\
\text { ivil }\end{array}$ \\
\hline $\begin{array}{l}\text { R.O. de } 16 \text { mayo } \\
1930\end{array}$ & $\begin{array}{l}\text { No se consideran actos oficiales procesiones y } \\
\text { solemnidades religiosas }\end{array}$ \\
\hline
\end{tabular}

\subsubsection{República}

La nueva estructura de poder rompe con el régimen anterior al tiempo que lanza un mensaje de cambio. Una de sus metas fue desterrar la identificación Estado-Iglesia como elemento legitimador de la Monarquía. Así, la Constitución de diciembre de 1931 acuerda que el Estado no tiene religión oficial, suprime el apoyo a la Iglesia y disuelve algunas compañías religiosas.

El 11 de mayo (1931) y ante la pasividad del Gobierno, un grupo incontrolado incendia nueve iglesias y conventos en Madrid.

Pero el mensaje de cambio no fue recibido de forma homogénea por el pueblo: unos quisieron servirse del mismo para hacer la revolución; otros, pensaron que la Patria se resquebrajaba... y la sombra de la Guerra Civil comenzaría a sobrevolar. Para efectuar el cambio, la República se servirá 
principalmente de la legislación, pero atendiendo un orden de prioridades temporal como refleja la tabla $n^{\circ} 2$ :

Durante los primeros días se promulgan una batería de normas para anular las representaciones plásticas más evidentes de la estructura de poder anterior: la simbología. A golpe de decreto se modifica la bandera, vigente en los buques de la Armada por Real Decreto (R.D.) de Carlos III, de 28 de mayo 1875, y se impone el lábaro tricolor así como el escudo de la I República.

Se deroga toda norma que orbite alrededor del binomio ceremonial-protocolo vigente; suprime las centenarias Órdenes de Caballería de Santiago, Montesa, Alcántara y Calatrava; y disuelve el tribunal de las Ordenes Militares y las Reales Maestranzas, entre otras. García Mercadal, F. (2016: 3), al tratar sobre la fuerza consoladora de los símbolos señala:

"Los emblemas políticos despliegan una función ordenadora, estabilizadora y conservadora de la realidad social y de los órganos de gobierno. Las necesidades y contingencias humanas son suturadas simbólicamente en el poder legitimador de los escudos, himnos, banderas, premios y distinciones [...], que refuerzan el imaginario colectivo, dando coherencia interna a las instituciones y ofreciendo a los ciudadanos una sensación de protección, armonía y continuidad".

En los meses siguientes se abre la etapa de reafirmación identitaria y se crea la Orden de la República, al objeto de premiar al ciudadano que se distinga en servir a España; la Orden Civil de África, para hacerlo por los servicios en el Protectorado de Marruecos o en territorios coloniales ${ }^{8}$, la Ciudadanía de Honor, etc. También ve la luz la nueva Constitución de 9 diciembre.

Tabla $n^{\circ} 2$ : Normativa relevante promulgada II. Fuente Elaboración propia9.

\begin{tabular}{|l|l|}
\hline NORMATIVA & LEGISLA SOBRE: \\
\hline $\begin{array}{l}\text { Decreto 22 y } 23 \text { abril } \\
1931\end{array}$ & $\begin{array}{l}\text { Promesa adhesión a la República por Ejército y } \\
\text { Marina }\end{array}$ \\
\hline $\begin{array}{l}\text { Orden de } 25 \text { abril } \\
1931\end{array}$ & $\begin{array}{l}\text { Modificando el Reglamento Honores del R.D. de } 4 \\
\text { enero 1922 }\end{array}$ \\
\hline
\end{tabular}




\begin{tabular}{|c|c|}
\hline $\begin{array}{l}\text { Decreto de } 27 \text { abril } \\
1931\end{array}$ & $\begin{array}{l}\text { Adoptando la Bandera Tricolor y el Escudo del } \\
\text { Gobierno de } 1869\end{array}$ \\
\hline $\begin{array}{l}\text { Decreto de } 29 \text { abril } \\
1931\end{array}$ & $\begin{array}{l}\text { Supresión Órdenes Santiago, Montesa, Alcántara y } \\
\text { Calatrava... }\end{array}$ \\
\hline $\begin{array}{l}\text { Orden Circular } 5 \text { mayo } \\
1931\end{array}$ & De los gallardetes de los buques de la Armada. \\
\hline $\begin{array}{l}\text { Decreto de } 8 \text { mayo } \\
1931\end{array}$ & Del juramento/promesa miembros del Poder Judicial \\
\hline $\begin{array}{l}\text { Decreto de } 13 \text { mayo } \\
1931\end{array}$ & $\begin{array}{l}\text { Crea Consejo director de las Asambleas de las } \\
\text { Ordenes Militares de San Fernando y San } \\
\text { Hermenegildo }\end{array}$ \\
\hline $\begin{array}{l}\text { Decreto de } 25 \text { mayo } \\
1931\end{array}$ & De reorganización del Ejército. \\
\hline $\begin{array}{l}\text { Decreto de } 16 \text { junio } \\
1931\end{array}$ & De creación e las Divisiones Orgánicas \\
\hline $\begin{array}{l}\text { Decreto de } 28 \text { agosto } \\
1931\end{array}$ & $\begin{array}{l}\text { Creación Escuadrón Caballería de Escolta al Pte. } \\
\text { República }\end{array}$ \\
\hline $\begin{array}{l}\text { Decreto de } 10 \text { octubre } \\
1931\end{array}$ & Nuevo Reglamento Orden Isabel la Católica \\
\hline $\begin{array}{l}\text { Constitución de } 9 \text { dic } \\
1931\end{array}$ & Aprueba Constitución de 9 diciembre 1931 \\
\hline Decreto de 9 dic 1931 & $\begin{array}{l}\text { Acto Promesa ante las Cortes de S.E. Presidente } \\
\text { República }\end{array}$ \\
\hline $\begin{array}{l}\text { Orden de } 17 \text { mayo } \\
1932\end{array}$ & $\begin{array}{l}\text { Supresión símbolos monárquicos en Academias del } \\
\text { Estado. }\end{array}$ \\
\hline $\begin{array}{l}\text { Decreto de } 21 \text { julio } \\
1932\end{array}$ & De creación de la Orden de la República \\
\hline $\begin{array}{l}\text { Decreto de } 12 \text { agosto } \\
1932\end{array}$ & $\begin{array}{l}\text { Presidencia honor Consejo Órdenes Isabel Católica y } \\
\text { la República }\end{array}$ \\
\hline $\begin{array}{l}\text { Decreto de } 28 \text { marzo } \\
1933\end{array}$ & $\begin{array}{l}\text { Ceremonia promesa fidelidad de la Marina a la } \\
\text { Bandera }\end{array}$ \\
\hline
\end{tabular}




\begin{tabular}{|l|l|}
\hline $\begin{array}{l}\text { Decreto de 26 octubre } \\
1933\end{array}$ & Creación Orden Civil de África \\
\hline $\begin{array}{l}\text { Decreto de } 23 \text { marzo } \\
1934\end{array}$ & Creación Ciudadanía de Honor \\
\hline $\begin{array}{l}\text { Decreto de } 30 \text { octubre } \\
1934\end{array}$ & Creación Corbata de la Orden de la República \\
\hline $\begin{array}{l}\text { Decreto de 22 de } \\
\text { mayo } 1936\end{array}$ & Creación de la Guardia Presidencial \\
\hline
\end{tabular}

En ese esfuerzo por tejer un ceremonial propio, se promulgan reglas provisionales que trataron de ajustar prelaciones y secuencias en los actos solemnes, sin embargo se trató el ceremonial de cada acto de forma individualizada (Mesa y Glöbel, JM. 2016: 76). Ejemplo de ello es la Orden Circular de 9 diciembre (1931) programando el Acto de Promesa en las Cortes de Alcalá Zamora, primer Presidente, diseñado con toda la suntuosidad posible al igual que lo estuvo el Acto de Promesa de Azaña ${ }^{10}$ años después.

Destacar que los mensajes no verbales implícitos a los actos de la República, se procuró que llegaran no solo a los invitados directos, sino al mayor número posible de ciudadanos; para ello, los cortejos diseñados fueron suntuosos y las carreras elegidas recorrerían toda la ciudad. La inestabilidad de los sucesivos gobiernos puede que originase la falta de esa norma escrita que reglara las precedencias de las autoridades.

\subsubsection{Dictadura franquista}

La estructura de poder percibió de inmediato que la Iglesia era un poderoso aliado y asumió la lucha como una cruzada contra la República. La Iglesia apoyó al dictador, posiblemente, por los años de legislación anticlerical (19311936) y por la nula represión de la violencia ejercida contra el clero. A falta de una Constitución el Régimen elaboró a lo largo de treinta años (1938-1967) las conocidas Leyes Fundamentales del Reino ${ }^{11}$.

Franco desde un principio busca su legitimación, dentro y fuera de España, aunque su primera victoria política se la proporciona la Santa Sede firmando el Concordato Español de 1953, en el que España se declara Estado confesional católico ${ }^{12}$ logrando el reconocimiento internacional.

Significar que tanto la bandera como el escudo fueron restituidos por Franco, en la llamada Zona Nacional; y que al término de la guerra, restituyo las normas protocolarias abolidas; entre ellas, se encuentran disposiciones 
comprendidas entre la Regencia $\mathrm{M}^{\mathrm{a}}$ Cristina de Borbón y la Regencia de $\mathrm{M}^{\mathrm{a}}$ Cristina de Habsburgo. (Tabla $n^{\circ} 3$ )

Balandier, G. (1994: 23), argumenta que "Las manifestaciones del poder se adaptan mal a la simplicidad y son la grandeza o la ostentación, la etiqueta o el fasto, el ceremonial o el protocolo lo que suele caracterizarlas". Ejemplo fue el Desfile de la Victoria del 19 de mayo de 1939 o la ceremonia en la iglesia de Santa Bárbara, cuando Franco entra al templo con su esposa, vestido de capitán general y bajo palio, para oír la Santa Misa y ofrendar la espada de la victoria. En la etapa inicial de la Dictadura, se promulgaría:

Reglamento de Actos y Honores Militares por decreto de 24 de julio $1943^{13}$. El Título III dedica el Cap. I a los honores al Santísimo Sacramento y a imágenes sagradas, aunque esto no representa novedad, puesto que las Reales Ordenanzas de Carlos III, en el siglo XVIII, determinaban este tipo de honores.

Nuevo Reglamento de Insignias, Banderas y Distintivos (Decreto de 11 octubre de 1945), que detalla las características de la Bandera Nacional en buques y edificios.

Ley Fundamental de Sucesión, de 26 de julio de 1947, que constituye a España en Reino. nuevamente, y le autoriza a elegir sucesor a la Corona.

Durante treinta años Franco estuvo pendiente del ceremonial, pero no se preocupó de legislar la prelación de autoridades hasta que intuyó su final. Otero Alvarado, MT (2015), argumenta que "El protocolo, a diferencia del ceremonial, aparece en sociedades avanzadas que necesitan ordenar la presencia del Estado en aras a la transmisión de conceptos, como sus jerarquías o su justicia, independientemente, del carácter democrático o totalitario de su estructura".

Tabla $n^{\circ}$ 3: Normativa relevante promulgada III. Fuente Elaboración propia.

\begin{tabular}{|c|c|}
\hline NORMATIVA & LEGISLA SOBRE: \\
\hline $\begin{array}{l}\text { Decreto de } 29 \text { agosto } \\
1936\end{array}$ & Que recupera la bandera nacional \\
\hline $\begin{array}{l}\text { Decreto de } 27 \text { de } \\
\text { febrero } 1937\end{array}$ & $\begin{array}{l}\text { Sobre oficialidad del himno nacional (Marcha } \\
\text { Granadera) }\end{array}$ \\
\hline $\begin{array}{l}\text { Decreto } 470 \text { de } \quad 2 \\
\text { febrero } 1938\end{array}$ & Sobre el Nuevo Escudo \\
\hline
\end{tabular}




\begin{tabular}{|c|c|}
\hline $\begin{array}{llll}\text { Orden de } & 10 & \text { abril } \\
1942 & & & \end{array}$ & $\begin{array}{l}\text { Lugar que han de ocupar los Fiscales de Tasas } \\
\text { en actos públicos }\end{array}$ \\
\hline $\begin{array}{llll}\text { Decreto de } 17 \text { julio } \\
1942\end{array}$ & $\begin{array}{l}\text { Declara que el Himno Nacional será la Marcha } \\
\text { Granadera }\end{array}$ \\
\hline $\begin{array}{l}\text { Decreto de } 31 \text { marzo } \\
1943\end{array}$ & $\begin{array}{l}\text { corresponde al Presidente de } \\
\text { as }\end{array}$ \\
\hline $\begin{array}{l}\text { Decreto } 21 \text { dic. } 1943 . \\
\text { Art. } 5^{\circ}\end{array}$ & e Trabajo \\
\hline $\begin{array}{lll}\begin{array}{l}\text { Decreto } \\
1945\end{array} & 11 & \text { octubre } \\
\end{array}$ & $\begin{array}{l}\text { Nuevo Reglamento de insignias, banderas y } \\
\text { distintivos }\end{array}$ \\
\hline $\begin{array}{l}\text { Decreto de } 8 \text { junio } \\
1947\end{array}$ & n \\
\hline $\begin{array}{l}\text { Orden de } 2 \text { octubre } \\
1951\end{array}$ & $\begin{array}{l}\text { n de prelación de los Ministerios } \\
\text { es }\end{array}$ \\
\hline $\begin{array}{l}\text { Decreto de } 27 \text { febrero } \\
1953\end{array}$ & Colegios Abogados \\
\hline $\begin{array}{lcc}\text { Decreto } & \text { de } & 14 \\
\text { noviembre } & 1957\end{array}$ & $\begin{array}{l}\text { ex Ministros en recepciones y } \\
\text { ficiales }\end{array}$ \\
\hline $\begin{array}{l}\text { Decreto } 10 \\
\text { 1958. Art. } 8^{\circ}\end{array}$ & $\begin{array}{l}\text { Que regula el Estatuto de los Gobernadores } \\
\text { Civiles }\end{array}$ \\
\hline $\begin{array}{l}\text { Decreto de } 6 \text { julio } \\
1961\end{array}$ & istros. \\
\hline $\begin{array}{l}\text { Decreto } 895 \text { de } 25 \\
\text { abril } 1963\end{array}$ & 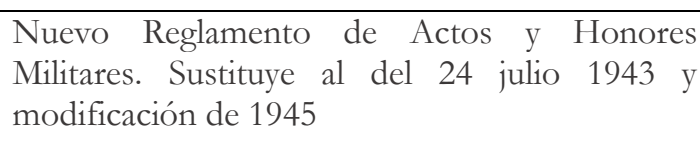 \\
\hline $\begin{array}{l}\text { Decreto 1483/1968 } 27 \\
\text { junio }\end{array}$ & $\begin{array}{l}\text { Reglamento Precedencias/Ordenación } \\
\text { Autoridades y Corporac. }\end{array}$ \\
\hline $\begin{array}{l}\text { Ley } 62 / 1969 \text {, de } 22 \\
\text { julio }\end{array}$ & $\begin{array}{l}\text { Provee a Juan Carlos de Borbón sucesor de la } \\
\text { Jefatura Estado. }\end{array}$ \\
\hline $\begin{array}{l}\text { Decreto } 2622 \text { de } 12 \\
\text { sept. } 1970\end{array}$ & $\begin{array}{l}\text { Mod. Reglamento de } \\
\text { Ordenación Autoridades }\end{array}$ \\
\hline
\end{tabular}




\begin{tabular}{|l|l|l|}
\hline $\begin{array}{l}\text { Decreto } 814 \text { de } 22 \\
\text { abril } 1971\end{array}$ & Guion y Estandarte Príncipe de España \\
\hline
\end{tabular}

En la etapa final se promulgaría:

El Decreto 1483/1968, de 27 junio $^{14}$, que aprueba el Reglamento de Precedencias y Ordenación de Autoridades y Corporaciones ${ }^{15}$. Por primera vez se dispone de una norma que clasifica los actos en oficiales y privados, excluyendo a los segundos del reglamento. Determina que los oficiales (generales/especiales), serán los que celebren festividades, acontecimientos nacionales, provinciales o locales que organicen las autoridades competentes. Respecto a la presidencia, dicta que será única y que se determinará a quién corresponde según el acto, pero en la misma estarán representadas autoridades del ámbito civil, eclesiástico, militar y judicial.

En cuanto a criterio de ordenación, dicta que el cargo prevalece sobre la categoría personal (novedoso); y establece un sistema de representación de autoridades abierto a la interpretación y complica el sistema de ordenación (Martínez-Correcher, J. 2014).

Finalmente, La Ley 62/1969, de 22 julio, que provee a SAR el príncipe D. Juan Carlos de Borbón como sucesor de la Jefatura del Estado, que encarriló el futuro de España.

El ceremonial de Estado siempre supo adaptarse a los intereses del Régimen. El ejército tuvo una importante presencia en los actos oficiales y también en los religiosos, donde brilló con fuerza el simbolismo de la estructura de poder franquista. Muñiz Velázquez, J.A. (1998: 396), argumenta que "El eje comunicativo del sistema propagandístico de la estructura franquista fue el ceremonial. Las ceremonias, acompañadas con la proclamación de festividades por doquier, marcaron la cotidianeidad de estas décadas".

\subsubsection{Monarquía parlamentaria de Juan Carlos I}

Muerto Franco las incertidumbres afloran en una sociedad que no ve cómo será el tránsito de una estructura de poder dictatorial a una democrática, pero el 6 de diciembre de 1978 se aprueba la nueva Consitición Española (CE) y se adopta la Monarquía Parlamentaria como forma de gobierno. El pueblo queda representado por las Cortes en un sistema bicameral, Congreso-Senado, siendo éste último la cámara de representación territorial de un Estado descentralizado. La CE marca la división de poderes (legislativo, ejecutivo y judicial); y surgen nuevas instituciones y las autoridades que guiarán sus pasos. 
Destacar que el artículo 16,3 dicta que "Ninguna confesión tendrá carácter estatal. Los poderes públicos tendrán en cuenta las creencias religiosas de la sociedad española y mantendrán las consiguientes relaciones de cooperación con la Iglesia católica y las demás confesiones".

El día del deceso del Caudillo se promueve al empleo de Capitán General de los Ejércitos a SAR el Príncipe de España y se restablece el Registro de Estado Civil de la Familia Real (Tabla no 4). Días después, en las Cortes, el Príncipe jura su cargo sobre los Evangelios ataviado con uniforme militar: algo normal dado que el protocolo lo marca el Régimen. En realidad, el Régimen seguía vivo en la figura del nuevo Jefe del Estado, por lo que no fue preciso cambiar la simbología hasta el año 1981, en que se adopta el nuevo Escudo de España.

Pero con la nueva organización territorial del Estado de las Autonomías, la norma del año 1968 era difícil de aplicar y se vivieron años de confusión protocolaria. El Gobierno socialista de Felipe González, según MartínezCorrecher (2014), "se percató del problema", y se promulga un nuevo ordenamiento de precedencias (1983).

La normativa más importante con respecto al protocolo en la etapa juancarlista es la siguiente:

Reglamento de Banderas y Estandartes, Guiones, Insignias y Distintivos ${ }^{16}$, de 1977, muy necesario ante los cambios de la Nación (el anterior databa de 1945).

R.D. 2157/1977 de 23 julio, por el que se crea el distintivo de la Casa de S.M. el Rey.

Reglamento de Honores Militares (R.D. 834/1984, de 11 abril), sobre los honores que corresponden a la bandera de España, a la familia real, autoridades civiles y militares, etc. Derogado R.D. 684/2010, que simplifica los honores sin afectar a las tradiciones.

R.D. 2099/1983 de 4 agosto, aprobando el Ordenamiento General de Precedencias en el Estado. El prólogo hace alusión a la nueva estructura de poderes e instituciones, unipersonales o colegiados. Este Ordenamiento trata de resolver la prelación de autoridades y dicta la clasificación y el tratamiento de los actos oficiales, el régimen de la presidencia de los mismos y los rangos de ordenación, según se contemple una ordenación personal, departamental o colegiada de Instituciones o Corporaciones.

R. D. 838/1996, de 10 de mayo, que reestructura el Gabinete y la Secretaría General de la Presidencia del Gobierno y suprime la Jefatura de Protocolo del Estado. 
Además del Estado, las Comunidades Autónomas (CC.AA.) y las Entidades Locales (EE.LL), han promulgado normas de protocolo aplicables en su territorio para blindar sus escudos, himnos y banderas; y con los años la normativa se ha multiplicado. Además han reglado el orden de prelación de sus autoridades en actos territoriales como muestra la tabla $n^{\circ} 5$.

Tabla $n^{\circ}$ 4: Normativa relevante promulgada IV. Fuente Elaboración propia.

\begin{tabular}{|c|c|}
\hline NORMATIVA & LEGISLA SOBRE: \\
\hline $\begin{array}{l}\text { Decreto Ley 16/1975 de } \\
20 \text { nov. }\end{array}$ & $\begin{array}{l}\text { Promueve a Capitán General de los Ejércitos de } \\
\text { Tierra, Mar y Aire a SAR el Príncipe de España }\end{array}$ \\
\hline $\begin{array}{l}\text { Decreto Ley } 17 / 1975 \text { de } \\
20 \text { nov. }\end{array}$ & $\begin{array}{l}\text { Se restablece el Registro de Estado Civil de la } \\
\text { Familia Real }\end{array}$ \\
\hline $\begin{array}{l}\text { Decreto } 2938 \text { de } 29 \text { nov. } \\
1975\end{array}$ & $\begin{array}{l}\text { Convoca a las Cortes para juramento de SAR D. } \\
\text { Juan Carlos }\end{array}$ \\
\hline $\begin{array}{llll}\begin{array}{l}\text { Decreto } \\
\text { enero }\end{array} & 54 / 1977 \text { de } 21 \\
\end{array}$ & $\begin{array}{l}\text { Sobre títulos y denominaciones del Heredero a } \\
\text { la Corona }\end{array}$ \\
\hline $\begin{array}{l}\text { R.D.1511/ } 1977 \text { de } 21 \\
\text { enero }\end{array}$ & $\begin{array}{l}\text { Aprueba Reglamento de Banderas, Insignias y } \\
\text { Distintivos }\end{array}$ \\
\hline $\begin{array}{l}\text { R.D. } 2157 / 1977 \text { de } 23 \\
\text { julio }\end{array}$ & $\begin{array}{l}\text { Se crea el distintivo de la Casa de Su Majestad el } \\
\text { Rey }^{17}\end{array}$ \\
\hline Constitución de 1978 & Constitución \\
\hline $\begin{array}{l}\text { R.D. } 2917 / 1981 \text { de } 27 \\
\text { noviembre }\end{array}$ & $\begin{array}{l}\text { Se diferencia entre la Familia Real y Familia del } \\
\text { Rey }\end{array}$ \\
\hline $\begin{array}{l}\text { Ley } 33 / 1981 \text {, de } 5 \text { de } \\
\text { octubre }\end{array}$ & Del Escudo de España \\
\hline $\begin{array}{l}\text { R.D. 2099/1983 de } 4 \\
\text { agosto }\end{array}$ & $\begin{array}{l}\text { Ordenamiento General de Precedencias en el } \\
\text { Estado }\end{array}$ \\
\hline R.D. 834/1984 de 11 abril & Reglamento de Honores Militares ${ }^{18}$ \\
\hline
\end{tabular}




\begin{tabular}{|l|l|}
\hline R.D 1368/1987 de 6 nov. & $\begin{array}{l}\text { Títulos, tratamientos y honores Familia Real y } \\
\text { Regentes }^{19}\end{array}$ \\
\hline R.D. 434/1988 de 6 mayo & Reestructuración de la Casa de S.M. el Rey \\
\hline $\begin{array}{l}\text { R.D. 838/1996 de } 10 \\
\text { mayo }\end{array}$ & Suprime la Jefatura de Protocolo del Estado \\
\hline $\begin{array}{l}\text { R.D. 1560 de } 10 \text { octubre } \\
1997\end{array}$ & $\begin{array}{l}\text { Regula que el Himno Nacional es la Marcha } \\
\text { Granadera }\end{array}$ \\
\hline $\begin{array}{l}\text { R.D. 284/2001 de } 16 \\
\text { marzo }\end{array}$ & $\begin{array}{l}\text { Crea el guion y estandarte de SAR Príncipe } \\
\text { Asturias }\end{array}$ \\
\hline $\begin{array}{l}\text { R.D. 913/2002 de } \\
\text { septiembre }\end{array}$ & $\begin{array}{l}\text { Sobre representación institucional de las Fuerzas } \\
\text { Armadas }\end{array}$ \\
\hline
\end{tabular}

El artículo 189 del Reglamento de Organización, Funcionamiento y Régimen Jurídico de las Entidades Locales ${ }^{20}$, dicta que éstas podrán crear medallas, condecoraciones, emblemas u otros distintivos honoríficos a fin de premiar especiales merecimientos, beneficios señalados o servicios extraordinarios. $\mathrm{Y}$ el artículo 190, especifica que los Ayuntamientos, Diputaciones Provinciales y Cabildos y Consejos Insulares, estarán facultados para acordar nombramientos de hijos predilectos y adoptivos y de miembros honorarios de la Corporación, atendidos los méritos y circunstancias que en los galardonados concurran y que serán aplicados con rigor en expediente que se instruirá al efecto.

Para García Mercadal, F. (2016: 2), las CA.AA y las EE.LL “[...] se han lanzado desde hace años, presas de una irreflexiva incontinencia normativa, a una desenfrenada carrera por innovar en estos asuntos ceremoniales y protocolarios, invocando el derecho de autorregulación”.

Tabla n $^{\circ}$ 5: Normativa protocolaria de las CC.AA. Fuente Elaboración propia.

\begin{tabular}{|l|l|}
\hline $\begin{array}{l}\text { COMUNIDAD } \\
\text { AUTÓNOMA }\end{array}$ & NORMATIVA COMUNITARIA \\
\hline Cataluña & Decreto $189 / 1981$, de 2 julio $^{21}$ \\
\hline Navarra & Decreto Foral $81 / 1986$, de 14 marzo $^{22}$ \\
\hline
\end{tabular}




\begin{tabular}{|c|c|}
\hline Murcia & Decreto 37/1992, de 23 abril \\
\hline Islas Canarias & Decreto 202/1997, de 2 agosto \\
\hline Valencia & Decreto 235/1999, de 23 diciembre ${ }^{23}$. \\
\hline Islas Baleares & $\begin{array}{l}\text { Decreto } 256 / 1999 \text {, de } 24 \text { diciembre y Orden de } \\
2 \text { julio } 2001\end{array}$ \\
\hline La Rioja & $\begin{array}{l}\text { Ley } 1 / 2001 \text {, de } 16 \text { marzo y Decreto 43/2001, de } \\
11 \text { octubre }\end{array}$ \\
\hline Andalucía & Decreto $77 / 2002$, de 26 febrero \\
\hline Ciudad Autónoma Ceuta & Acuerdo, de 22 enero 2007 \\
\hline Ciudad Autónoma Melilla & Decreto 111, de 22 marzo 2007 \\
\hline
\end{tabular}

\subsubsection{Reinado de Felipe VI: posmodernismo}

En junio de 2014, tras la abdicación del Monarca, el Juancarlismo toca a su fin y se aplica el artículo 57 de la CE, que legitima la subida al trono de Felipe VI en un momento complejo en el que la sombra de la corrupción y el desprestigio planean sobre una Familia Real que pasa a tener ya solo seis miembros.

Se promulga el R.D. 470/2014, de 13 junio, modificando el régimen de títulos, tratamientos y honores de la Familia Real. Los Monarcas anteriores, con títulos honoríficos de Rey y Reina, y trato de Majestad, pasan a ocupar el lugar inmediato posterior a los descendientes de Felipe VI en el Ordenamiento de 1983. Una norma que, tras treinta y cuatro años, algunos expertos como Fuente Lafuente, C. (2006a) reclaman su revisión por considerarla "inaplicable en la mayoría de ámbitos".

Este autor también propone listas alternativas que recogen un mayor número de autoridades que las especificadas en los artículos 10 y 12 del RD 2099/1983, suprimiendo autoridades desaparecidas e incluyendo nuevos cargos que están fuera de lugar en los actos oficiales (Lafuente, C. 2006b: 122 a 127). 
La globalización exige a la Monarquía adaptarse a este tiempo líquido o posmodernidad donde las nuevas tecnologías posibilitan que el binomio ceremonial-protocolo viaje por las redes sociales a toda velocidad. Así, la Casa de S.M el Rey debe gestionar este binomio con una precisión milimétrica para cada acto, y con grandes dosis de austeridad, dado el desafecto a la Corona y a los símbolos de la Nación de una parte considerable de la ciudadanía.

Mansilla Ferret, H. (2001:11), al hablar de los últimos apéndices posmodernistas, recoge parte de esta idea cuando afirma: "La decadencia de la dimensión simbólica ha conllevado un empobrecimiento inocultable de la civilización actual, y éste tiene que ver directamente con el decaimiento de las tradiciones aristocráticas (...)".

Y en esta misma línea apunta Piñeiro Rodríguez, S. (2015: 6) 24:

“[...], existe un considerable número de compatriotas que han sido «educados», desde bien pequeños, para no abrazar —ni por asomo- los símbolos de nuestra Nación; además, cada uno de ellos ha tenido, y tiene, una motivación diferente para que así sea. Unos no se identifican en lo más mínimo con los acordes del himno nacional, dado el férreo nacionalismo que se respiraba en casa, llegada la hora de comer; o en el colegio, a lo largo de esas curiosas clases de historia. Otros, no han tenido ocasión alguna de admitir en su pensamiento la figura de un rey, independientemente de que se trate de Juan Carlos I o Felipe VI, a consecuencia de su pertenencia a un ancestral árbol genealógico republicano. Otros cuantos, republicanos también pero con poca genealogía, tampoco se tratan con la rojaygualda y veneran la tricolor".

\section{Metodología}

La forma de profundizar en las representaciones plásticas más evidentes de las estructuras de poder en España, así como en el binomio ceremonial-protocolo entre 1917 y 2017, ha sido mediante una tarea participada de algunas de las fases de una investigación en la que el objetivo sea estudiar un fenómeno: documentación, recopilación de datos, análisis documental, descripción, resultados y conclusiones. El método para realizar el estudio tiene un marcado carácter descriptivo y se ofrece una amplia relación de las normas promulgadas en las etapas consideradas, lograda a través de la búsqueda, consulta y análisis documental de fuentes de la época y trabajos de autores reconocidos.

Los recursos y las fuentes de consulta esenciales para su desarrollo han sido: 
La Gaceta de Madrid, Colección Histórica, disponible en la página web del BOLETÍN Oficial del Estado.

La hemeroteca del diario Abc de Madrid, disponible en la página web del periódico

La colección del Boletín Oficial del Estado, disponible en la página web del BOE

Martínez-Correcher, y Gil, J. Cuatro protocolos en la reciente historia de España. Conferencia de clausura del I Congreso Internacional El Protocolo Contemporáneo. 25.04.2014.

Artículo de Mesa y Glöbel, JM. Segunda República, ceremonial y protocolo, publicado en la revista de Estudios Institucionales vol. 3, nº 5 (2016).

\section{Resultados}

Los tres cambios de estructura de poder (1917-2017), implicaron tres variantes en la forma de gestionar simbología, ceremonial y protocolo.

\subsection{De monarquía a república}

La II República, buscando su legitimación, liquida la bandera que Isabel II institucionalizó, el escudo del Gobierno de 1968 y la Marcha Granadera. En abril de 1931, oficializa la tricolor y timbra el escudo con corona mural retirando los símbolos monárquicos. Así mismo, modifica el anterior Reglamento de Honores ${ }^{25}$ y suprime las Órdenes de Caballería, entre otras. El Himno de Riego, oficiosamente, es considerado como himno nacional desde el principio.

A base de decretos se pasa de un ceremonial palatino, de carácter borgoñón, a otro hecho a medida para cada acto. La suntuosidad adquiere gran importancia y ceremonias como la Promesa del Presidente ante las Cortes se realizan con el máximo boato posible y procurando siempre el posterior baño de multitudes.

La normativa de ordenación alfonsina, donde prima la nobleza frente a las autoridades; así como la prelación llevada a cabo durante la dictadura de Rivera, para recepciones y Besamanos en cualquier parte del territorio, quedan anuladas. En su lugar se impone un orden piramidal en los distintos actos a celebrar basado en la nueva estructura de poder, pero no dejará norma general escrita.

\subsection{De república a dictadura}

Franco concede una importancia capital a las representaciones plásticas del poder y antes de consolidarlo, recupera para la Zona Nacional la bandera rojigualda y la Marcha Granadera, aunque adopta un escudo basado en la 
iconografía heráldica de los Reyes Católicos. Tras su victoria, una cruzada inteligente contra la infiel República, restituye la normativa de derecho premial y protocolo abolida y devuelve poder a la Iglesia. Promulga también un Reglamento de Actos y Honores Militares (1943) y otro de Insignias, Banderas y Distintivos (1945).

Para legitimar su caudillaje se sirvió del ceremonial, como herramienta principal, y lo comparte abiertamente con la cúpula militar y con la del Movimiento. El ejército pasa a tener una importante presencia en los actos oficiales y también en los religiosos, puesto que la iglesia recupera su presencia en los mismos y permite que la pompa y el simbolismo del poder franquista, brille con luz propia.

Respecto a las normas, dado que Franco restituye la prelación palatina, la aplica de forma sibilina treinta años en función de sus intereses. En 1968, en aras a perpetuar la trasmisión de su impronta y ordenar la presencia del Estado en los actos, promulga el Decreto 1483, y se establece por primera vez una clasificación de actos, con presidencia única; aderezado de un sistema de representación de autoridades demasiado abierto e interpretable que complica la prelación.

\subsection{De dictadura a monarquía}

La reinstauración de la Monarquía es un cambio esperado donde la sombra del Régimen sobrevive en la figura del nuevo Jefe de Estado, también Rey, y no se precisa el cambio de símbolos arraigados; solo incorporar las armas reales al Escudo de la Nación con la Ley 33/1981.

En la etapa preconstitucional el ceremonial sigue las pautas del Régimen, con la salvedad de que es el Monarca quien desfila bajo palio o preside los actos, ahora, menos pomposos. Luego, la globalización, el creciente desafecto a los símbolos y las redes de comunicación obligan a la Casa Real a gestionarlo con minuciosidad milimétrica y austeridad.

En cuanto a normativa, el Reglamento de Precedencias de 1968 continua haciendo estragos, y aviva el caos protocolario, al coincidir en actos las emergentes autoridades del Estado con las casi extintas del Régimen. El problema solo se resolverá años después con el Real Decreto 2099/1983, de Ordenamiento General de Precedencias en el Estado.

\subsection{Relación de orden temporal}

La II República impuso las representaciones plásticas de su estructura de poder los primeros días, aboliendo las anteriores; y a golpe de decreto diseña 
el ceremonial de cada uno de los actos solemnes, pero no dejó por escrito norma general de prelación. La Dictadura, también impuso sus símbolos de inmediato; luego, durante treinta años aplica un ceremonial a la carta y a su conveniencia, pero no se preocupa de legislar la prelación de autoridades hasta que surge la necesidad. Con la reinstauración de la Monarquía, el Régimen sobrevive de alguna forma en la figura del Rey y nuevo Jefe de Estado, no siendo preciso cambio de simbología. Se aplica el ceremonial anterior, con menos boato y, promulgada la Constitución de 1978, surge la necesidad de una norma que ordene a las autoridades de la nueva estructura de poder.

La consolidación de una nueva estructura de poder necesita legitimarse, para ello, inicialmente impone sus símbolos como representaciones plásticas más evidentes. Acto seguido, remodela a su criterio el ceremonial y la escenificación de los actos más o menos solemnes y; finalmente, trata de perpetuar en norma escrita la prelación de sus autoridades. Por tanto, pude hablarse de una relación de orden temporal, entre el proceso de asentamiento de una nueva estructura de poder y la paulatina transformación del trinomio simbología-ceremonial-protocolo.

\subsection{Cambios de normativa protocolaria}

Alfonso XIII intervino en la prelación en las recepciones en el Salón del Trono (1908) y Primo de Rivera lo hizo en las recepciones para Besamanos donde no residían SS.MM. (1926). Queda el aire el que la II república no dejara escrita norma general de ordenación, probablemente, a causa de la escasa duración de sus numerosos gobiernos. También es evidente que cuando Franco siente necesidad de reglar el orden de precedencias de su estructura de Estado (1968), lo hace; al igual que sucede al Gobierno de Felipe González (1983).

Se infiere pues, que las normas generales de ordenación protocolaria en España de los últimos ciento diez años, cambiaron cuando varió la situación política, social o económica o cuando el poder político sintió necesidad y estuvo dispuesto al cambio.

\section{Conclusiones}

Tanto la II República como la Dictadura gestionaron la imposición de su simbología, de forma clara e inmediata, para legitimarse como estructura de poder. La planeada Monarquía de 1975, con su nuevo Jefe de Estado y Rey al frente, solo precisó incorporar con el tiempo las armas reales al Escudo Nacional dado el arraigo de los otros símbolos del Estado.

Respecto al ceremonial, la República lo gestiona individualmente en cada uno de sus actos, a golpe de decreto, sin escatimar suntuosidad; mientras que la 
Dictadura lo impregna siempre de la máxima pompa, para legitimar la imagen y poder de su Caudillo. La Monarquía se deja llevar en la etapa preconstitucional y, después, lo gestiona con austeridad y con precisión quirúrgica, sabedora de la repercusión de los medios de comunicación en este posmodernismo actual.

Con la II República no cristaliza una norma escrita de ordenamiento, probablemente, por la inestabilidad de sus gobiernos; y la Dictadura aplica en un principio normas de precedencia monárquicas a conveniencia, pero al final deja escrita una prelación de autoridades (1968). En la Monarquía Parlamentaria de la Constitución de 1978, surge la necesidad de promulgar una norma de prelación de las nuevas autoridades del Estado y se promulga el RD 2099/1983, de Ordenamiento General de Precedencias en el Estado.

La consolidación de una nueva estructura de poder impone de inmediato sus símbolos como representaciones plásticas más evidentes. Después, será la escenificación y el ceremonial de los actos los que serán remodelados al uso y; finalmente, si es posible, se tratará de perpetuar en norma escrita la ordenación de autoridades de la estructura. Por tanto, pude hablarse de una relación de orden temporal, entre el proceso de asentamiento de una nueva estructura de poder y la paulatina transformación que sufre el trinomio simbologíaceremonial-protocolo.

Alfonso XIII intervino en la ordenación de las recepciones en el Salón del Trono (1908) y Primo de Rivera lo hizo en las recepciones donde no residían SS.MM. (1926). Es obvio que cuando Franco siente necesidad de perpetuar la prelación de su estructura de Estado (1968), lo hace; al igual que le sucede al Gobierno de Felipe González (1983). Queda el aire que la II República no dejara escrita norma general de prelación, como consecuencia de la inestabilidad política. Se infiere pues, que las normas generales de ordenación protocolaria de un país cambian cuando varía la situación política, social o económica del mismo; o cuando el poder político siente la necesidad de modificarlas.

Nos encontrarnos inmersos en un posmodernismo líquido y globalizado en el que las señas identitarias de la Nación se diluyen con el embate de populismos, nacionalismos y recientes regionalismos que les andan a la zaga, a los que poco importan los símbolos de la Nación, los ceremoniales o las inveteradas tradiciones, dado que aparentemente solo persiguen su cuota de protagonismo mediático y, tal vez, de poder.

Hoy, puede que sea buen momento para alumbrar cualquier norma de protocolo a nivel regional o incluso local; pero no se intuye ánimo alguno en el Gobierno de España por modificar el R.D. 2099/1983, de Ordenamiento 
General de Precedencias, aunque algunos expertos consideren que es inaplicable ya en la mayoría de ámbitos.

Bajo el punto de vista protocolario, teniendo en cuenta las estructuras de poder consideradas, pudiera quedar abierta una línea de investigación respecto al antagónico papel representado por la Iglesia Católica y sus símbolos durante el periodo considerado.

\section{Bibliografía}

Almagro de San Martín, M. (1946). Crónica de Alfonso XIII y su linaje, Madrid. Atlas.

Balandier, G. (1994) Le pouvoir sur scènes (El poder en escenas). Barcelona. Paidós Studio.

Bauman, Z. (2007). Liquid Times. Living in an Age of Uncertainty (Tiempos líquidos. Vivir en una época de incertidumbre). México. TusQuets.

Carasa Soto, P. (1991) Alfonso XIII y la Segunda República (1898-1936). Madrid. Ed. Gredos

Diario Abc. Hemeroteca. En: http://hemeroteca.abc.es.

Diario Oficial Ministerio de Guerra núm. 245, de 1 noviembre 1922. pp. 487496.

Fredric, J. (1991). Postmodernism, or The Cultural Logic of Late Capitalism. Barcelona. Paidos.

Fuente Lafuente, C. (2006a). Las asignaturas pendientes del protocolo Oficial. Rev. Internacional de Protocolo. Madrid. (Núm. 39). Abril-junio

-(2006b) Protocolo Oficial. Las instituciones españolas del Estado y su ceremonial. Oviedo. (5 Edición). Ed. Protocolo. Pp: 122-127.

García Mercadal, F. (2016) Código de ceremonial y protocolo. Madrid. BOE. Edición actualizada 16 enero 2016. www.boe.es/legislación/códigos/

Gaceta de Madrid. Colección Histórica en: www.boe.es/buscar/gazeta.php. Madrid. BOE

Giraud, E. (1938) Le pouvoir exécutif dans les démocraties d'Europe et d'Amérique. Paris. Librairie du recueil Sirey. En García Canales, M. (1987). La prerrogativa regia en el reinado de Alfonso XIII. Revista de Estudios Políticos. Madrid. (Núm. 55). Enero-Marzo 1987. 
Gómez Navarro, J. L. (1991). El régimen de Primo de Rivera: Reyes, dictaduras y dictadores. Madrid. Cátedra.

González Cuevas, PC. El Rey y la Corte. En Moreno Luzón, J. (2003: 203). Madrid. Marcial Pons Historia.

Mansilla Ferret, H. (2001) Lo razonable de la tradición: una revisión crítica de algunos principios premodernos. Rev. Estudios Políticos (Nueva Época) Madrid. (N¹13). Julio 2001.

Martínez-Correcher, y Gil, J. (1997). Siglo XX: del antiguo al nuevo protocolo español. Revista Internacional de Protocolo. Madrid. (Núm. 7). pp. 28-30.

--(2002) El protocolo en España: ayer y hoy. Acto de inauguración del curso 2002/03 en la Facultad de Comunicación de la Universidad de Sevilla. Consultado [23.03.2017] en https://www.protocolo.org/

--(2014) Clausura del I Congreso Internacional Protocolo Contemporáneo. Madrid 25 de abril 2014. Cuatro protocolos en la reciente historia de España. En: https://www.youtube.com/watch?v=xbLI-ENNiio

Mesa y Glöbel, JM. (2016) Segunda República, ceremonial y protocolo. Revista Estudios Institucionales. Madrid. (Vol. 3, $n^{\circ}$ 5) [pp. 23-78] Consulta en http://revistaeeii.eu/

Muñiz Velázquez, J.A. (1998). La Música en el Sistema Propagandístico Franquista. Revista Historia y Comunicación Social UCM. Madrid. (Núm. 3).

Otero Alvarado, M.T. (2000). Teoría y estructura del ceremonial y el protocolo. Sevilla. Mergablum

--(2015) La historia del Protocolo. Barcelona. UOC. Párrafo $6^{\circ}$ punto 2.3 El Franquismo. Consultado [28.03.1017] https://books.google.es/

Piñeiro Rodríguez, S. (2015) El ninguneo a los símbolos. Cartagena. Diario La Opinión 20.07.2015. p.6.

Real Diccionario de la Lengua Española. Edición octubre de 2014.

Redondo Gálvez, G. (1993). Historia de la Iglesia en España 1031-1939. Madrid. Rialp. 


\section{Notas}

${ }^{1}$ Vigésimo cuarta edición octubre 2014. http://dle.rae.es/ Consultado [24.02.2017].

${ }^{2}$ Sociólogo y filosofo polaco (1925-2017)

${ }^{3}$ Añadido del autor.

${ }^{4}$ Giraud, E. Le pouvoir exécutif dans les démocraties d'Europe et d'Amérique. En: García Canales, M. (1987).

${ }^{5}$ Hemeroteca Abc. consulta [20.03.2017] en: http://hemeroteca.abc.es

${ }^{6}$ D.O. del Ministerio de Guerra núm. 245, 1 noviembre 1922. pp. 487-496.

${ }^{7}$ Gaceta Madrid. Núm. 26 (26 enero 1908). p. 357

${ }^{8} \mathrm{La}$ Orden de Isabel la Católica ${ }^{8}$ perduró con un nuevo reglamento por su vínculo centenario con países Suramericanos.

${ }^{9}$ Colecciones históricas BOE citadas en Mesa Göbel, JM. (2016) [Consultado el 29.03.2017] en:

http://revistas.uned.es/index.php/EEII/article/view/18391/pdf_49

${ }^{10}$ Regulado por Orden de 7 mayo y Orden Circular de 8 mayo, 1936

${ }^{11}$ Se pueden consultar en

http://www.hispanidad.info/1967leyesfundamentalesrefundidas.htm

${ }^{12}$ El Estado se compromete a sufragar los gastos de Iglesia, pero asegura

participar en nombramiento de obispos vía el derecho de presentación (habitual en monarquías absolutas).

13 Modificado en 1945 y en 1963 por Decreto 895/1963, de 25 de abril.

${ }^{14}$ BOE núm. 167, 12 julio 1968, pp. 10153 a 56. https://www.boe.es/. [Consulta 10.03.2017]

${ }^{15}$ Modificado por Decreto 2622/1970, incluyendo la figura del Heredero a la Corona

16 BOE núm. 156, de 1 julio 1977.

${ }_{17}$ Modificado por R.D. 725/1993, de 14 mayo. 
18 Modificado por R.D. 684/2010, de 20 mayo, que aprueba el Reglamento de Honores Militares.

${ }_{19}$ Modificado por R.D. 470/2014, de 13 junio.

20 Aprobado por R.D. 2568/1986, de 28 noviembre.

21 Modificado por Decreto 459/1981, de 6 noviembre, por inconstitucionalidad de alguno de sus artículos.

22 Modificado por Decreto Foral 333/2001, de 26 noviembre.

${ }^{23}$ Modificado por Decreto 9/2003 y Decreto 77/2003, de 27 junio.

${ }^{24}$ El ninguneo a los símbolos. Artículo diario La Opinión. Cartagena. 20.07.2015. p.6.

25 Aprobado por R.D. de 4 de enero 1922. 


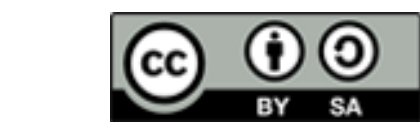

Licencia Creative Commons

Miguel Hernández Communication Journal

mhjournal.org

\section{Cómo citar este texto:}

Serafín Piñeiro Rodríguez (2017): "Ceremonial y protocolo: el tránsito al posmodernismo", en Miguel Hernández Communication Journal, nº, pp. 319 a 345. Universidad Miguel Hernández, UMH (Elche-Alicante). Recuperado el _ de de 20__ de: Џink

del artículo en mhjournal.org] 
